\title{
Long non-coding RNAs: Novel links in respiratory diseases (Review)
}

\author{
YANRU LIU, RUIFENG ZHANG and KEJING YING \\ Department of Respiratory Medicine, Sir Run Run Shaw Hospital, Medical School of Zhejiang University, \\ Hangzhou, Zhejiang 310016, P.R. China
}

Received April 3, 2014; Accepted December 12, 2014

DOI: $10.3892 / \mathrm{mmr} .2015 .3290$

\begin{abstract}
Long non-coding RNAs (lncRNAs) represent a surprisingly novel field in mammalian transcriptome research. With the development of RNA sequencing technology and computational methods, IncRNAs have been demonstrated to have important roles in biological processes at the epigenetic, transcription and post-transcriptional levels. In addition, the dysregulation of lncRNAs contributes to numerous diseases, including cancer and cardiovascular diseases. The present review discusses the important functions of lncRNAs in respiratory diseases, highlights the mechanistic roles which underlie lncRNAs in lung cancer as well as considers the current and future potential use of lncRNAs as novel biomarkers and therapeutic targets for the treatment of lung cancer.
\end{abstract}

\section{Contents}

1. Introduction

2. LncRNA in lung development

3. LncRNA in lung inflammation

4. LncRNA and cigarette smoke

5. LncRNA and lung cancer

6. LncRNA and pulmonary hypertension

7. LncRNA and lung fibrosis

8. Conclusion

\section{Introduction}

The central principle of molecular biology considers RNA as the intermediaries between DNA sequences and their encoded proteins (1). However, due to the vast amounts and variety of

Correspondence to: Professor Kejing Ying, Department of Respiratory Medicine, Sir Run Run Shaw Hospital, Medical School of Zhejiang University, 3 East Qingchun Road, Hangzhou, Zhejiang 310016, P.R. China

E-mail: ykjsrrsh@126.com

Key words: long non-coding RNAs, respiratory diseases, lung cancer non-coding RNA transcripts uncovered by advances in RNA sequencing technology and computational methods, it has been elucidated that numerous non-coding (nc)RNA transcripts have important roles in a variety of biological processes. ncRNAs are conventionally divided into two major classes based on transcript size; small ncRNAs and long (1)ncRNAs (2). Small ncRNAs are represented by the well-documented miRNAs, which are 22 nucleotides(nt) in length (2). By contrast, lncRNAs are messenger (m)RNA-like transcripts, which range in length from $200 \mathrm{nt}$ to 100 kilobases $(\mathrm{kb})$ and lack significant open reading frames (2).

In the last decade, numerous studies have shown that lncRNAs were able to regulate gene expression at the levels of epigenetics, transcription and post-transcriptional processes (3) (Fig. 1). LncRNAs have been reported to mediate epigenetic changes by recruiting chromatin-modifying complexes to specific genomic loci or tumor cell-specific promoter regions (4). For example, Hox transcript antisense RNA (HOTAIR), which is derived from the HOXC locus, interacts with the polycomb repressive complex 2 (PRC2) in order to regulate their target genes in cancer (5); in addition, IncRNAs were shown to interact with transcription factors or act as transcriptional co-regulators in order to mediate the process of transcription. Furthermore, lncRNAs directly interact with RNA polymerase II in order to regulate transcription (3). LncRNAs have also been recognized as effective regulators of pre-mRNA splicing, mRNA decay and translation (6).

To date, several techniques have been used for discovery, identification and detection of lncRNAs. The predominantly used techniques include microarrays, RNA sequencing (RNA-seq), Northern blotting, reverse transcription quantitative polymerase chain reaction (RT-qPCR), in situ hybridization, bioinformatics prediction and target sequencing (Table I). Scientists have created databases providing comprehensive annotations of lncRNAs in order to fully elucidate the functions of lncRNAs in diseases and to identify potential lncRNAs which may be used as diagnostics, therapeutics and prognostic markers (Table II).

Of note, several human diseases have been demonstrated to be associated with mutated and dysregulated lncRNA expression, including numerous types of cancer (18-23), cardiovascular diseases (24-26) and neurological diseases (27-29). Candidate lncRNAs, including prostate 


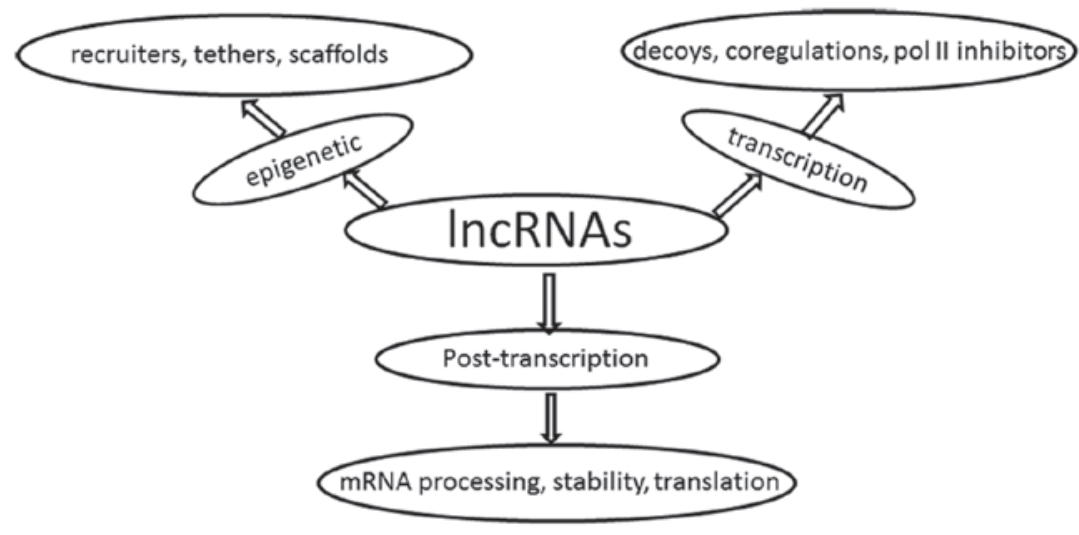

Figure 1. Roles of lncRNAs in the regulation of gene expression. Epigenetic function: Recruit or tether to the epigenome, or act as scaffolds for chromatin modification. Transcription function: Act as decoys for 'sponge' protein factors in order to suppress gene expression as well as act as transcription co-regulators or bind with pol II inhibitors in order to regulate transcription. Post-transcription function: Regulate the levels of mRNA processing, stability and translation. LncRNA, long non-coding RNA; Pol II, RNA polymerase II; mRNA, messenger RNA.

Table I. Methods for discovery, identification and detection of lncRNAs.

Method

Characteristics

Northern blotting

Verifies the existence of novel lncRNAs

Low sensitivity, time consuming

Requires relatively large amounts of total RNA

RT-qPCR

Validates the existence of novel lncRNAs with high sensitivity and specificity

Cannot discover novel lncRNAs

In situ hybridization

Can locate lncRNA in tissue and cell compartments

Low sensitivity and quantification

RNA sequencing

Can be employed for high throughput discovery of novel lncRNAs and transcriptome analysis Expensive; requirement of large number of data for analysis

Microarrays

Can be effective for high-throughput analysis of lncRNA expression

Usually the results rely on the PCR

Bioinformatic prediction

Target sequencing

Can give helpful information for further exploration and reduce experimental cost

Combined multiplexed and target-specific amplification process with a high-throughput sequencing technology

lncRNA, long non-coding RNA; RT-qPCR, reverse transcription-quantitative polymerase chain reaction.

cancer-associated 3 and urothelial cancer-associated 1, have been regarded as potential biomarkers for the diagnosis of prostate and bladder cancer, respectively $(21,30)$. The present review focuses on the emerging roles of lncRNAs in lung diseases.

\section{LncRNA in lung development}

Human lung development may be subdivided into five distinct stages: Embryonic, pseudoglandular, canalicular, terminal saccular and alveolar (31). During the first stage, the lung primordium develops from the foregut. Thereafter, the original lung buds further branch into a larger number of smaller areas. The canalicular stage is characterized by enlargement of the bronchi and vascularization of the lung tissue. Alveolar ducts and air sacs are established during the saccular phase.
At the final stage, the terminal saccules, alveolar ducts and alveoli increase in number (31). It has been demonstrated that microRNAs have important roles during early and late lung development $(32,33)$. However, the functions of lncRNAs in lung development remain to be elucidated. Alveolar capillary dysplasia with misalignment of pulmonary veins (ACD/MPV) is a rare, congenital lung development malformation, which results in pulmonary veins adjacent to small pulmonary arteries, medial thickening of small pulmonary arteries, deficient lobular development, insufficient alveolar wall capillaries and occasionally lymphangiectasis (34). ACD/MPV has been associated with Forkhead box protein F1 (FOXF1) on 16q24.1, which is predominantly expressed in mesenchymal tissues of the developing lungs $(35,36)$. Szafranski et al (37) demonstrated that the loss of a small non-coding gene region at $16 \mathrm{q} 24.1$, including lncRNAs, led to the development of ACD/MPV. 
Table II. Long non-coding RNA databases.

Name

Website

Reference

Non-coding RNA database
fRNAdb
NRED
LncRNAdb
ncFANs
NONCODE
CHIPBase
LNCipedia
DIANA-LncBase
LncRNADisease
lncRNome

http://biobases.ibch.poznan.pl/ncRNA/

http://www.ncrna.org/frnadb/

http://jsm-research.ibm.uq.edu.au/nred/cgi-bin/ncrnadb.pl

http://www.lncrnadb.org/

http://www.ebiomed.org/ncFANs/

http://www.noncode.org/NONCODERv3/

http://deepbase.sysu.edu.cn/chipbase/

http://www.Incipedia.org

http://www.microrna.gr/LncBase

http://cmbi.bjmu.edu.cn/lncrnadisease

http://genome.igib.res.in/lncRNome

Therefore it was proposed that the FOXF1 promoter was regulated by the interplay between chromatin looping, which may be mediated by lncRNAs and methylation-controlled glioma-associated oncogene family zinc finger 2 (GLI2) (37). Overall, previous studies have indicated that lncRNAs may be responsible for numerous disorders of human development.

\section{LncRNA in lung inflammation}

The immune system protects the body against organisms and foreign substances which may cause infections and diseases. The immune system is divided into the innate and adaptive immune systems (38). Inflammation is one of the first responses of the immune system to infection. LncRNAs have been demonstrated to have important roles in innate and adaptive immunity, including regulation of the differentiation of immune cell subsets and their immunological functions (39-46).

Activation of the innate immune system and pathological inflammation are the first steps in the protection of the human body against a vast number of microorganisms (47). The respiratory epithelial surface is exposed to an enormous number of foreign substances, including allergens and pathogens. Toll-like receptors (TLRs) are a type of pattern recognition receptor (PRR) (48). TLR signaling is known to be involved in pathogen recognition and the activation of innate immune cell responses following the invasion of microbes across physical barriers, including the skin and surfaces of other organs (49-50). Large intergenic non-coding RNA (lincRNA)-Cox 2 , which is induced by TLRs, interacts with various regulatory complexes, including heterogeneous nuclear ribonucleoproteins (hnRNP)-A/B and A2/B1, in order to regulate immune genes (39). Rapicavoli et al (40) reported that the expression of a pseudogene lncRNA called Lethe increased when tumor necrosis factor (TNF)- $\alpha$ activated the pro-inflammatory factory transcription factor nuclear factor $(\mathrm{NF})-\kappa \mathrm{B}$. In addition, Lethe interacts with the $\mathrm{NF}-\kappa \mathrm{B}$ subunit RelA in order to prevent DNA binding and reduce the expression of various inflammatory proteins (40). Innate immune system anti-viral host defense is mediated by type I interferon (IFN) induction and signaling machinery (51). IFN, produced primarily from dendritic cells, establishes an effective anti-viral state in cells. It was reported that signal transducer and activator of transcription factor 1 (STAT1) may be a key modulator of IFN signaling and have a key role in clearance of severe acute respiratory syndrome coronavirus (SARS-CoV) in the innate response (52). Peng et al (41) demonstrated the widespread differential expression of lncRNA in response to viral infections, which were found to be involved in innate immunity. These results were obtained through performing qPCR on lung samples from mice lacking the IFN (IFNAR-/-) or STAT1 (STAT1-/-), which were infected with SARS-CoV (41).

LncRNA expression has been identified to be involved during the development and differentiation of T cells. TMEVPG1, a novel lincRNA, was first identified using a positional cloning approach in Theiler's viral infection (42). Collier et al (43) reported that TMEVPG1 is a type 1 T-heper (Th1)-specific lincRNA which is regulated by STAT4 and T-box expressed in $\mathrm{T}$ cells (T-bet) and was found to be involved in the transcription of the gene encoding IFN- $\gamma$. A further study demonstrated that TMGVPG1 contributed to histone methylation at the Ifng locus in CD8+ T cells via interactions with WDR5 (44). In a study by Pang et al (45), hundreds of lncRNAs were found to be expressed in mammalian CD8+ T cells, several of which surrounded or overlapped with the expression of important protein-coding genes, which indicated their possible function as regulatory decoy genes. In addition, $\mathrm{Hu}$ et al (46) revealed highly dynamic and cell-specific expression patterns for lincRNAs during $\mathrm{T}$ cell differentiation. LincR-Ccr2-5'AS, a lincRNA regulated by GATA-3, was reported to be an important component in gene expression specific to the Th2 subset of $\mathrm{T}$ helper ( $\mathrm{Th}$ ) cells as well as the migration of Th2 cells (46).

\section{LncRNA and cigarette smoke}

Cigarette smoke is a significant risk factor for the development of lung diseases, including lung cancer, chronic obstructive pulmonary disease (COPD) and emphysema (53). Several lncRNAs have been demonstrated to be differentially expressed between smokers and non-smokers. One of these lncRNAs was 
significantly increased in epithelia of smokers and was also associated with lung cancer (54). This lncRNA was therefore named smoke and cancer-associated lncRNA-1 (SCAL1). In addition, SCAL1 was found to be a key downstream mediator of NF erythroid 2-related factor 2 (Nrf-2) in the regulation of genes responsible for oxidative stress protection (54). Nrf-2 was demonstrated to be a transcription factor which protected against the cytotoxic effects of oxidative stress (55). Imprinted genes inherit a single allele, while the other allele is not or only weakly expressed. The H19 gene was reported to be highly expressed during embryonic development and strongly downregulated in the majority of tissues following birth (56). H19 is one of the most highly conserved imprint genes, which has been shown to have important roles in normal development as well as oncogenesis $(57,58)$. Kaplan et al (59) demonstrated that IncRNA H19 expression was significantly increased in the bronchial epithelial cells of smokers due to activation of a H19 single allele, rather than due to loss of imprinting (LOI). Furthermore, previous studies have shown that LOI of H19 was associated with lung cancer $(60,61)$. Therefore, IncRNA H19 and SCAL1 may be potential biomarkers for the early diagnosis of lung cancer in smokers.

\section{LncRNA and lung cancer}

Lung cancer is the leading cause of cancer-associated mortality worldwide. To date, no early detection mechanisms have been elucidated and the current therapeutic strategies for lung cancer treatment are ineffective; as a result, the mortality rate of this disease is high. Recent studies have indicated that lncRNAs may have an important role in the development and progression of lung cancer $(62,63)$. The primary lncRNAs which have been associated with lung cancer to date include metastasis-associated lung adenocarcinoma transcript (MALAT)-1, H19, growth arrest-specific gene 6 antisense RNA 1 (GAS-AS1), HOTAIR and MEG3.

Development of lung cancer. LOI refers to the loss of parental-origin-specific differential allele expression (64). LOI has been considered to be abundant and precocious in the development of human tumors (64). Overexpression of H19 has been observed in lung cancer with LOI of H19 $(60,61)$. Barsyte-Lovejoy et al (65) demonstrated that the oncogene c-Myc bound to conserved E-boxes at the H19 promoter close to the imprinting control region and upregulated the expression of this lncRNA, which contributed to the tumorigenic phenotype of lung cancer cells. However, this study showed that the oncogene c-Myc did not affect the imprinting of H19, which remained to be monoallelic. In addition, the imprinted H19 lncRNA is a precursor of micRNA-675 (66), which has been shown to regulate the tumor suppressor retinoblastoma protein in order to induce tumorigenesis (67).

Epigenetics refers to the heritable changes in gene expression without permanent changes to the DNA sequence. These changes may include DNA methylation, histone modification and nucleosome positioning. Epigenetic alterations have been recognized to contribute to several pathological processes, including cancer (68). MEG3 is a tumor suppressor lncRNA gene; hypermethylation of the MEG3 promoter has been shown to contribute to the low expression of MEG3 in lung cancer (69). In addition, overexpression of MEG3 may induce reactivated p53 (69), which may indicate another potential mechanism of MEG3 in tumor suppression.

HOTAIR was proposed to be an oncogene due to its increased expression in several types of cancers, which was reported to promote invasion and metastasis (70-72). Type I collagen (Col-1), a type of interstitial extracellular matrix (ECM), was found to be abnormally enriched in the tumor microenvironment and promoted tumor activity (73). Zhuang et al (74) demonstrated that Col-1 induced the expression of HOTAIR in non-small-cell lung carcinoma (NSCLC) cells, which indicated that HOTAIR may contribute to the tumorigenesis of lung cancer.

LncRNA and lung cancer metastasis. MALAT-1 was first identified as a predictive marker for metastasis development in lung cancer (75); however, its role in metastasis remains to be elucidated. Tano et al (76) suggested that MALAT-1 promoted cell motility through transcriptional and post-transcriptional regulation of motility-associated gene expression. HOTAIR has been shown to have important roles in the metastasis of several types of human tumors, including lung cancer (77). HOTAIR was reported to interact with PRC2 and act as a co-repressor of silencing transcription factors in order to inhibit tumor metastasis-suppressor gene transcription, therefore increasing the risk of tumor metastasis (78).

LncRNA in the prognosis and treatment of lung cancer. A close association has been reported between high expression of MALAT1 and prognosis of lung cancer patients. Schmidt et al (79) demonstrated that the expression of MALAT-1 was associated with the prognosis of squamous cell carcinoma; however, it was independent of the prognosis of non-squamous cell carcinoma patients. In addition, downregulation of MALAT-1 may inhibit the metastasis and invasion of lung cancer cells (80). NSCLC patients with low expression of MEG3 were reported to have a poor prognosis (69). Therefore, MALAT-1 and MEG3 may be novel diagnostic prognostic markers for lung cancer. Growth arrest-specific 6 (GAS6) was shown to interact with the TAM (Axl, Tyro3/Sky and Mer) subfamily of receptor tyrosine kinases (81). GAS6 was found to be involved in biological processes, including proliferation, apoptosis and adhesion. In addition, lncRNA GAS6-AS1 expression was reported to be an independent risk factor for the overall survival and metastasis in NSCLC patients (82). Furthermore, IncRNA GAS6-AS1 was shown to be negatively correlated with GAS6 mRNA (82). These studies provided evidence to suggest that lncRNA GAS6-AS1 may be involved in NSCLC through regulating or interacting with its host gene GAS6.

Despite novel chemotherapeutic treatments and targeted drugs which have achieved great improvements in the treatment of lung cancer, the overall five-year survival rate of NSCLC has not improved (83). Chemoresistance is one of the most significant challenges for the successful treatment of lung cancer. In addition, the correlation of IncRNAs with chemoresistance has been demonstrated (84-86). HOTAIR was reported to contribute to cisplatin resistance in human lung adenocarcinoma cells through affecting apoptosis and cell cycle distribution via regulation of $\mathrm{p} 21$ expression (86). Studies have shown that lung adenocarcinoma cell resistance 
to cisplatin was associated with Nrf-2 as well as its downstream genes $(87,88)$. Thai et al (54) demonstrated that Nrf-2 activated the expression of SCAL1 through binding to the promoter, which suggested the possible role of Nrf-2 in lung cancer chemoresistance. Overall, these studies have indicated that lncRNAs may be potential drug targets for increasing the effectiveness of lung cancer treatment.

\section{LncRNA and pulmonary hypertension}

Pulmonary arterial hypertension (PAH) is a disease with numerous pathological and physiological factors, which has a poor prognosis and ineffective treatment options. $\mathrm{PAH}$ is characterized by increasing pulmonary artery pressure and elevated pulmonary vascular resistance, leading to right heart failure (89). Studies have revealed the complex nature of the disorder, including inflammation, hypoxia, dysregulated pulmonary endothelial cell proliferation and gene mutations (89-91).

The renin-angiotensin system (RAS) has been shown to cause endothelial dysfunction and vascular remodeling during the development of PAH (92). RAS is primarily composed of angiotensin-converting enzyme (ACE), angiotensin II (Ang II) and angiotensin II type 1 receptor (AT1R) (93). A recent study has identified a novel lncRNA, Lnc-Ang 362, which is differentially expressed in the response of vascular smooth muscle cells (VSMC) to Ang II; in addition, this novel lncRNA, as a host transcript for miR-221 and miR-222, was shown to have a crucial role in cell proliferation (94). Furthermore, these two microRNAs were previously reported to be associated with VSMC proliferation and the regulation of Ang II in endothelial cells $(95,96)$.

Inflammation may be another important factor which contributes to PAH due to the release of cytokines, chemokines and various growth factors that may result in cell proliferation. LncRNAs have been demonstrated to be involved in the regulation of inflammation and therefore may have an impact on the pathogenesis of PAH.

\section{LncRNA and lung fibrosis}

Idiopathic pulmonary fibrosis (IPF) is defined as chronic, progressive fibrotic interstitial pneumonia without a known cause. Until recently there were no effective drug therapies for the treatment of IPF. The disease is characterized by the expansion of activated mesenchymal cells and alveolar epithelial cell injury leading to excessive ECM protein deposition in the basement membrane and impaired gas exchange (97). Cao et al (98) established a model of bleomycin-induced lung fibrosis, in which they detected 568 differentially expressed lncRNAs in the bleomycin-treated lung samples compared with those in the normal control group through microarray analysis. In addition, levels of lncRNA AJ005396 and lncRNA S69206 were found to be significantly increased compared with those in the control animals (98).

Studies on IncRNAs associated with the pathogenesis of IPF are limited; however, the detection of mutated and dysregulated lncRNAs may elucidate potential molecular targets for the treatment of lung fibrosis, as IncRNAs have been demonstrated to have important roles in disease pathogenesis.

\section{Conclusion}

In conclusion, ncRNAs were previously thought of as 'noise'; however, following decades of research, evidence has been provided for the biological functions of ncRNA transcripts. In recent years, the functions of miRNAs in disease have been well documented; however, compared with that of studies into the dysregulation of miRNAs, current knowledge of the role of lncRNAs in disease is still the tip of the iceberg, as only a small portion of lncRNA functions have been elucidated. The present review described the involvement of lncRNAs in respiratory diseases, with a specific focus on lung cancer, as previous studies have demonstrated that IncRNAs have key regulatory roles in the pathogenesis of cancer. An in-depth understanding of the biological functions of lncRNAs and how they interact with other ncRNAs as well as target genes in lung cancer may elucidate novel biomarkers and therapeutic targets for the early diagnosis and treatment of lung cancer.

\section{References}

1. Crick FH, Barnett L, Brenner S and Watts-Tobin RJ: General nature of the genetic code for proteins. Nature 192: 1227-1232, 1961.

2. Gutschner T and Diederichs S: The hallmarks of cancer: a long non-coding RNA point of view. RNA Biol 9: 703-719, 2012.

3. Kung JT, Colognori D and Lee JT: Long noncoding RNAs: past, present, and future. Genetics 193: 651-669, 2013.

4. Atkinson SR, Marguerat S and Bähler J: Exploring long non-coding RNAs through sequencing. Semin Cell Dev Biol 23: 200-205, 2012.

5. Shi X, Sun M, Liu H, Yao Y and Song Y: Long non-coding RNAs: a new frontier in the study of human diseases. Cancer Lett 339: 159-166, 2013

6. Yoon JH, Abdelmohsen K and Gorospe M: Posttranscriptional gene regulation by long noncoding RNA. J Mol Biol 425: 3723-3730, 2013.

7. Erdmann VA, Szymansk Mi, Hochberg A, Groot ND and Barciszewski J: Non-coding, mRNA-like RNAs database Y2K. Nucleic Acids Res 28: 197-200, 2000.

8. Mituyama T, Yamada K, Hattori E, et al: The Functional RNA Database 3.0: databases to support mining and annotation of functional RNAs. Nucleic Acids Res 37: D89-D92, 2009.

9. Dinger ME, Pang KC, Mercer TR, Crowe ML, Grimmond SM and Mattick JS: NRED: a database of long noncoding RNA expression. Nucleic Acids Res 37: D122-D126, 2009.

10. Amaral PP, Clark MB, Gascoigne DK, Dinger ME and Mattick JS: LncRNAdb: a reference database for long noncoding RNAs. Nucleic Acids Res 39: D146-D151, 2011.

11. Liao Q, Xiao H, Bu DC, et al: ncFANs: a web server for functional annotation of long non-coding RNAs. Nucleic Acids Res 39: W118-W124, 2011.

12. Bu DC, Yu KT, Sun SL, et al: NONCODE v3.0: integrative annotation of long noncoding RNAs. Nucleic Acids Res 40: D210-D215, 2012.

13. Yang JH, Li JH, Jiang S, Zhou H and Qu LH: ChIPBase: a database for decoding the transcriptional regulation of long non-coding RNA and microRNA genes from ChIP-Seq data. Nucleic acids Res 41: D177-D187, 2013.

14. Volders PJ, Helsens K, Wang X, et al: LNCipedia: a database for annotated human IncRNA transcript sequences and structures. Nucleic acids Res 41: D246-D251, 2013.

15. Paraskevopoulou MD, Georgakilas G, Kostoulas N, Reczko M, Maragkakis M, Dalamagas TM and Hatzigeorgiou AG: DIANA-LncBase: experimentally verified and computationally predicted microRNA targets on long non-coding RNAs. Nucleic Acids Res 41: D239-D245, 2013.

16. Chen G, Wang ZY, Wang DQ, et al: LncRNADisease: a database for long-non-coding RNA-associated diseases. Nucleic Acids Res 41: D983-D986, 2013.

17. Bhartiya D, Pal K, Ghosh S, et al: lncRNome: a comprehensive knowledgebase of human long noncoding RNAs. Database (Oxford) 2013: bat034, 2013. 
18. Piao $\mathrm{H}$ and $\mathrm{Ma} \mathrm{L}$ : Non-coding RNAs as regulators of mammary development and breast cancer. J Mammary Gland Biol Neoplasia 17: 33-42, 2012.

19. Geng YJ, Xie SL, Li Q, Ma J and Wang GY: Large intervening non-coding RNA HOTAIR is associated with hepatocellular carcinoma progression. J Int Med Res 39: 2119-2128, 2011.

20. Kogo R, Shimamura T, Mimori K, et al: Long noncoding RNA HOTAIR regulates polycomb-dependent chromatin modification and is associated with poor prognosis in colorectal cancers. Cancer Res 71: 6320-6326, 2011.

21. Nilsson J, Skog J, Nordstrand A, Baranov V, Mincheva- Nilsson L, Breakefield XO and Widmark A: Prostate cancer-derived urine exosomes: a novel approach to biomarkers for prostate cancer. $\mathrm{Br}$ J Cancer 100: 1603-1607, 2009.

22. $\mathrm{Ng} \mathrm{D}$, Toure $\mathrm{O}$, Wei MH, et al: Identification of a novel chromosome region, 13q21.33-q22.2, for susceptibility genes in familial chronic lymphocytic leukemia. Blood 109: 916-925, 2007.

23. Huarte $M$ and Rinn JL: Large non-coding RNAs: missing links in cancer? Hum Mol Genet 19 (R2): R152-R161, 2010.

24. Holdt LM and Teupser D: Recent studies of the human chromosome 9p21 locus, which is associated with atherosclerosis in human populations. Arterioscler Thromb Vasc Biol 32: 196-206, 2012.

25. Liu Y, Sanoff HK, Cho H, et al: INK4/ARF transcript expression is associated with chromosome $9 \mathrm{p} 21$ variants linked to atherosclerosis. PLoS One 4: e5027, 2009.

26. Ishii N, Ozaki K, Sato H, et al: Identification of a novel non-coding RNA, MIAT that confers risk of myocardial infarction. J Hum Genet 51: 1087-1099, 2006.

27. Johnson R: Long non-coding RNAs in Huntington's disease neurodegeneration. Neurobiol Dis 46: 245-254, 2012.

28. Qureshi IA, Mattick JS and Mehler MF: Long non-coding RNAs in nervous system function and disease. Brain Res 1338: 20-35, 2010.

29. Decourt B and Sabbagh MN: BACE1 as a potential biomarker for Alzheimer's disease. J Alzheimers Dis 24 (Suppl 2): 53-59, 2011

30. Wang XS, Zhang Z, Wang HC, et al: Rapid identification of UCA1 as a very sensitive and specific unique marker for human bladder carcinoma. Clin Cancer Res 12: 4851-4858, 2006.

31. Zoetis T and Hurtt ME: Species comparison of lung development. Birth Defects Res B Dev Reprod Toxicol 68: 121-124, 2003.

32. Lü J, Qian J, Chen F, Tang X, Li C and Cardoso WV: Differential expression of components of the microRNA machinery during mouse organogenesis. Biochem Biophys Res Commun 334 319-323, 2005

33. Bhaskaran M, Wang Y, Zhang H, et al: MicroRNA-127 modulates fetal lung development. Physiol Genomics 37: 268-278, 2009.

34. Bishop NB, Stankiewicz P and Steinhorn RH: Alveolar capillary dysplasia. Am J Respir Crit Care Med 184: 172-179, 2011.

35. Stankiewicz P, Sen P, Bhatt SS, et al: Genomic and genic deletions of the FOX gene cluster on 16q24.1 and inactivating mutations of FOXF1 cause alveolar capillary dysplasia and other malformations. Am J Hum Genet 84: 780-791, 2009.

36. Mahlapuu M, Enerbäck S and Carlsson P: Haploinsufficiency of the Forkhead gene Foxf1, a target for sonic hedgehog signaling, causes lung and foregut malformations. Development 128 : 2397-2406, 2001.

37. Szafranski P, Dharmadhikari AV, Brosens E, et al: Small noncoding differentially methylated copy-number variants including lncRNA genes, cause a lethal lung developmental disorder. Genome Res 23: 23-33, 2013.

38. Getz GS: Bridging the innate and adaptive immune systems. J Lipid Res 46: 619-622, 2005.

39. Carpenter S, Aiello D, Atianand MK, et al: A long noncoding RNA mediates both activation and repression of immune response genes. Science 341: 789-792, 2013.

40. Rapicavoli NA, Qu K, Zhang JJ, Mikhail M, Laberge RM and Chang HY: A mammalian pseudogene lncRNA at the interface of inflammation and anti-inflammatory therapeutics. ELife 2: e00762, 2013.

41. Peng X, Gralinski L, Armour CD, et al: Unique signatures of long noncoding RNA expression in response to virus infection and altered innate immune signaling. mBio 1: e00206-e00210, 2010.

42. Vigneau S, Rohrlich PS, Rahic MB and Bureau JF: Tmevpg1, a candidate gene for the control of Theiler's virus persistence, could be implicated in the regulation of interferon. J Virol 77: 5632-5638, 2003.

43. Collier SP, Collins PL, Williams CL, Boothby MR and Aune TM: Cutting edge: influence of Tmevpg1, a long intergenic noncoding RNA, on the expression of Ifng by Th1 cells. J Immunol 189: 2084-2088, 2012.
44. GomeZ JA, Wapinski OL, Yang YW, et al: The NeST long ncRNA controls microbial susceptibility and epigenetic activation of the interferon- $\gamma$ locus. Cell 152: 743-754, 2013.

45. Pang KC, Dinger ME, Mercer TR, Malquori L, Grimmond SM, Chen W and Mattick JS: Genome-wide identification of long noncoding RNAs in CD8+ T cells. J Immunol 182: 7738-7748, 2009 .

46. Hu G, Tang Q, Sharma S, et al: Expression and regulation of intergenic long noncoding RNAs during $\mathrm{T}$ cell development and differentiation. Nat Immunol 14: 1190-1198, 2013.

47. Janeway CA Jr, Travers P, Walport M and Shlomchik M: Principles of innate and adaptive immunity. In: Immunobiology: The Immune System in Health and Disease. 5th edition. Garland Science, New York, NY, 2001.

48. Kawai T and Akira S: The role of pattern-recognition receptors in innate immunity: update on Toll-like receptors. Nature Immunol 11: 373-384, 2010.

49. Kawai T and Akira S: Toll-like receptor and RIG-1-like receptor signaling. Ann NY Acad Sci 1143: 1-20, 2008.

50. Medzhitov R and Horng T: Transcriptional control of the inflammatory response. Nat Rev Immunol 9: 692-703, 2009.

51. Liu SY, Sanchez DJ and Cheng G: New developments in the induction and antiviral effectors of type I interferon. Curr Opin Immunol 23: 57-64, 2011

52. Hogan RJ, Gao G, Rowe T, et al: Resolution of primary severe acute respiratory syndrome-associated coronavirus infection requires Stat1. J Virol 78: 11416-11421, 2004.

53. Rupani H, Sanchez-Elsner T and Howarth P: MicroRNAs and respiratory diseases. Eur Respir J 41: 695-705, 2013.

54. Thai P, Statt S, Chen CH, Liang E, Campbell C and Wu R: Characterization of a novel long noncoding RNA, SCAL1, induced by cigarette smoke and elevated in lung cancer cell lines. Am J Respir Cell Mol Biol 49: 204-211, 2013.

55. Kaspar JW, Niture SK and Jaiswal AK: Nrf2:INrf2 (Keap1) signaling in oxidative stress. Free Radical Biol Med 47: 1304-1309, 2009

56. Lustig O, Ariel I, llan J, Lev-Lehman E, De-Groot N and Hochberg A: Expression of the imprinted gene H19 in the human fetus. Mol Reprod Dev 38: 239-246, 1994.

57. Gabory A, Jammes H and Dandolo L: The H19 locus: role of an imprinted non-coding RNA in growth and development. Bioessays 32: 473-480, 2010.

58. Matouk IJ, DeGroot N, Mezan S, Ayesh S, Abu-lail R, Hochberg A and Galun E: The H19 non-coding RNA is essential for human tumor growth. PloS One 2: e845, 2007.

59. Kaplan R, Luettich K, Heguy A, Hackett NR, Harvey BG and Crystal RG: Monoallelic up-regulation of the imprinted H19 gene in airway epithelium of phenotypically normal cigarette smokers. Cancer Res 63: 1475-1482, 2003.

60. Kondo M, Suzuki H, Ueda R, Osada H, Takagi K and Takahashi T: Frequent loss of imprinting of the $\mathrm{H} 19$ gene is often associated with its overexpression in human lung cancers. Oncogene 10: 1193-1198, 1955.

61. Kondo $\mathrm{M}$ and Takahashi T: Altered genomic imprinting in the IGF2 and H19 genes in human lung cancer. Nihon Rinsho 54: 492-496, 1996 (In Japanese).

62. Xu G, Chen J and Pan Q: Long noncoding RNA expression profiles of lung adenocarcinoma ascertained by microarray analysis. PLoS One 9: e104044, 2014.

63. White NM, Cabanski CR, Silva-Fisher JM, Dang HX, Govindan R and Maher CA: Transcriptome sequencing reveals altered long intergenic non-coding RNAs in lung cancer. Genome Biol 13: 429, 2014.

64. Jelinic P and Shaw P: Loss of imprinting and cancer. J Pathol 221: 261-268, 2007.

65. Barsyte-Lovejoy D, Lau SK, Boutros PC, et al: The c-Myc oncogene directly induces the H19 noncoding RNA by allele-specific binding to potentiate tumorigenesis. Cancer Res 66: 5330-5337, 2006.

66. Cai X and Cullen BR: The imprinted H19 noncoding RNA is a primary microRNA precursor. Rna 13: 313-316, 2007.

67. Tsang WP, Ng EK, Ng SS, Jin H, Yu J, Sung JJ and Kwok TT: Oncofetal H19-derived miR-675 regulates tumor suppressor RB in human colorectal cancer. Carcinogenesis 31: 350-358, 2010.

68. Tim W and Feinberg AP: Cancer as a dysregulated epigenome allowing cellular growth advantage at the expense of the host. Nat Rev Cancer 13: 497-510, 2013.

69. Lu KH, Li W, Liu XH, et al: Long non-coding RNA MEG3 inhibits NSCLC cells proliferation and induces apoptosis by affecting p53 expression. BMC Cancer 13: 461, 2013. 
70. Gupta RA, Shah N, Wang KC, et al: Long non-coding RNA HOTAIR reprograms chromatin state to promote cancer metastasis. Nature 464: 1071-1076, 2010.

71. Yang Z, Zhou L, Wu LM, Lai MC, Xie HY,Zhang F and Zheng SS: Overexpression of long noncoding RNA HOTAIR predicts tumor recurrence in hepatocellular carcinoma patients following liver transplantation. Ann Surg Oncol 18: 1243-1250, 2011.

72. Kogo Shimamura T, Mimori K, et al: Long noncoding RNA HOTAIR regulates polycomb-dependent chromatin modification and is associated with poor prognosis in colorectal cancers. Cancer Res 71: 6320-6326, 2011.

73. Egeblad M, Rasch MG and Weaver VM: Dynamic interplay between the collagen scaffold and tumor evolution. Curr Opin Cell Biol 22: 697-706, 2010.

74. Zhuang Y, Wang X, Nguyen $\mathrm{H}$, et al: Induction of long intergenic non-coding RNA HOTAIR in lung cancer cells by type I collagen. J Hematol Oncol 6: 35, 2013 .

75. JiP,Diederichs S, Wang W, et al: MALAT-1, a novel noncoding RNA and thymosin beta4 predict metastasis and survival in early-stage non-small cell lung cancer. Oncogene 22: 8031-8041, 2003.

76. Tano K, Mizuno R, Okada T, et al: MALAT-1 enhances cell motility of lung adenocarcinoma cells by influencing the expression of motility-related genes. FEBS Lett 584: 4575-4580, 2010.

77. Nakagawa T, Endo H, YoKoyama M, et al: Large noncoding RNA HOTAIR enhances aggressive biological behavior and is associated with short disease-free survival in human non-small cell lung cancer. Biochem Biophys Res Commun 436: 319-324, 2013.

78. Tsai MC, Manor O, Wan Y, et al: Chang, Long noncoding RNA as modular scaffold of histone modification complexes Science 329: 689-693, 2010.

79. Schmidt LH, Spieker T, Koschmieder S, et al: The long noncoding MALAT-1 RNA indicates a poor prognosis in non-small cell lung cancer and induces migration and tumor growth. J Thorac Oncol 6: 1984-1992, 2011.

80. Gutschner T, Hämmerle M, Eissmann M, et al: The noncoding RNA MALAT1 is a critical regulator of the metastasis phenotype of lung cancer cells. Cancer Res 73: 1180-1189, 2013.

81. Lee Y, Lee M, and Kim S: Gas 6 induces cancer cell migration and epithelial-mesenchymal transition through upregulation of MAPK and Slug. Biochem Biophys Res Commun 434: 8-14, 2013.

82. Han L, Kong R, Yin DD, Zhang EB, Xu TP, De W, and Shu YQ: Low expression of long noncoding RNA GAS6-AS1 predicts a poor prognosis in patients with NSCLC. Med Oncol 30: 694, 2013.

83. Brody H: Lung cancer. Nature 513:S1, 2014.

84. Takahashi K, Yan IK, Kogure T, Haga H and Patel T: Extracellular vesicle-mediated transfer of long non-coding RNA ROR modulates chemosensitivity in human hepatocellular cancer. FEBS Open Bio 4: 458-467, 2014.
85. Fan Y, Shen B, Tan M, Mu X, Qin Y, Zhang F and Liu Y: Long non-coding RNA UCA1 increases chemoresistance of bladder cancer cells by regulating Wnt signaling. FEBS J 281: 1750-1758, 2014

86. Liu Z, Sun M, Lu K, et al: The long noncoding RNA HOTAIR contributes to cisplatin resistance of human lung adenocarcinoma cells via downregualtion of p21 (WAF1/CIP1) expression. PloS one 8: e77293, 2013

87. Sing A, Boldin-Adamasky S, Thimmulappa RK, et al: RNAi-mediated silencing of nuclear factor erythroid-2-related factor 2 gene expression in non-small cell lung cancer inhibits tumor growth and increases efficacy of chemotherapy. Cancer Res 68: 7975-7984, 2008

88. Oh S, Kim Y, Kim J, Kwon D and Lee E: Elevated pressure, a novel cancer therapeutic tool for sensitizing cisplatin-mediated apoptosis in A549. Biochem Biophys Res Commun 399: 91-97, 2010.

89. Voelkel NF, Gomez-Arroyo J, Abbate A, Bogaard HJ and Nicolls MR: Pathobiology of pulmonary arterial hypertension and right ventricular failure. Eur Respir J 40: 1555-1565, 2012.

90. Guignabert $\mathrm{C}$ and Dorfmuller P: Pathology and pathobiology of pulmonary hypertension. Semin Respir Crit Care Med 34: 551-559, 2013.

91. Caruso P, MacLean MR and Khanin R: Dynamic changes in lung microRNA profiles during the development of pulmonary hypertension due to chronic hypoxia and monocrotaline. Arteriosclerosis Thromb Vasc Biol 30: 716-723, 2010.

92. Lüscher TF: Endothelial dysfunction: the role and impact of the renin-angiotensin system. Heart 84 (Suppl 1): i20-i22, 2000.

93. Shenoy V, Qi Y, Katovich MJ and Raizada MK: ACE2, a promising therapeutic target for pulmonary hypertension. Curr Opin Pharmacol 11: 150-155, 2011.

94. Leung A, Trac C, Jin W, et al: Novel long noncoding RNAs are regulated by angiotensin II in vascular smooth muscle cells. Circ Res 113: 266-278, 2013

95. Zhu N, Zhang D, Chen S, et al: Endothelial enriched microRNAs regulate angiotensin II-induced endothelial inflammation and migration. Atherosclerosis 215: 286-293, 2011.

96. Liu X, Cheng Y, Zhang S, Lin Y, Yang J and Zhang C: A necessary role of miR-221 and miR-222 in vascular smooth muscle cell proliferation and neointimal hyperplasia. Circ Res 104: 476-487, 2009.

97. Noble PW and Homer RJ: Back to the future: historical perspective on the pathogenesis of idiopathic pulmonary fibrosis. Am J Respir Cell Mol Biol 33: 113-120, 2005.

98. Cao G, Zhang J, Wang M, Song X, Liu W, Mao C and Lv C: Differential expression of long non-coding RNAs in bleomycin-induced lung fibrosis . Int J Mol Med 32: 355-364, 2013. 